\title{
CARCINOMA OF THE THYROID
}

\author{
By Selwyn Taylor, M.Ch., F.R.C.S.
} Surgeon and Leciurer in Surgery, Postgraduate School of London *
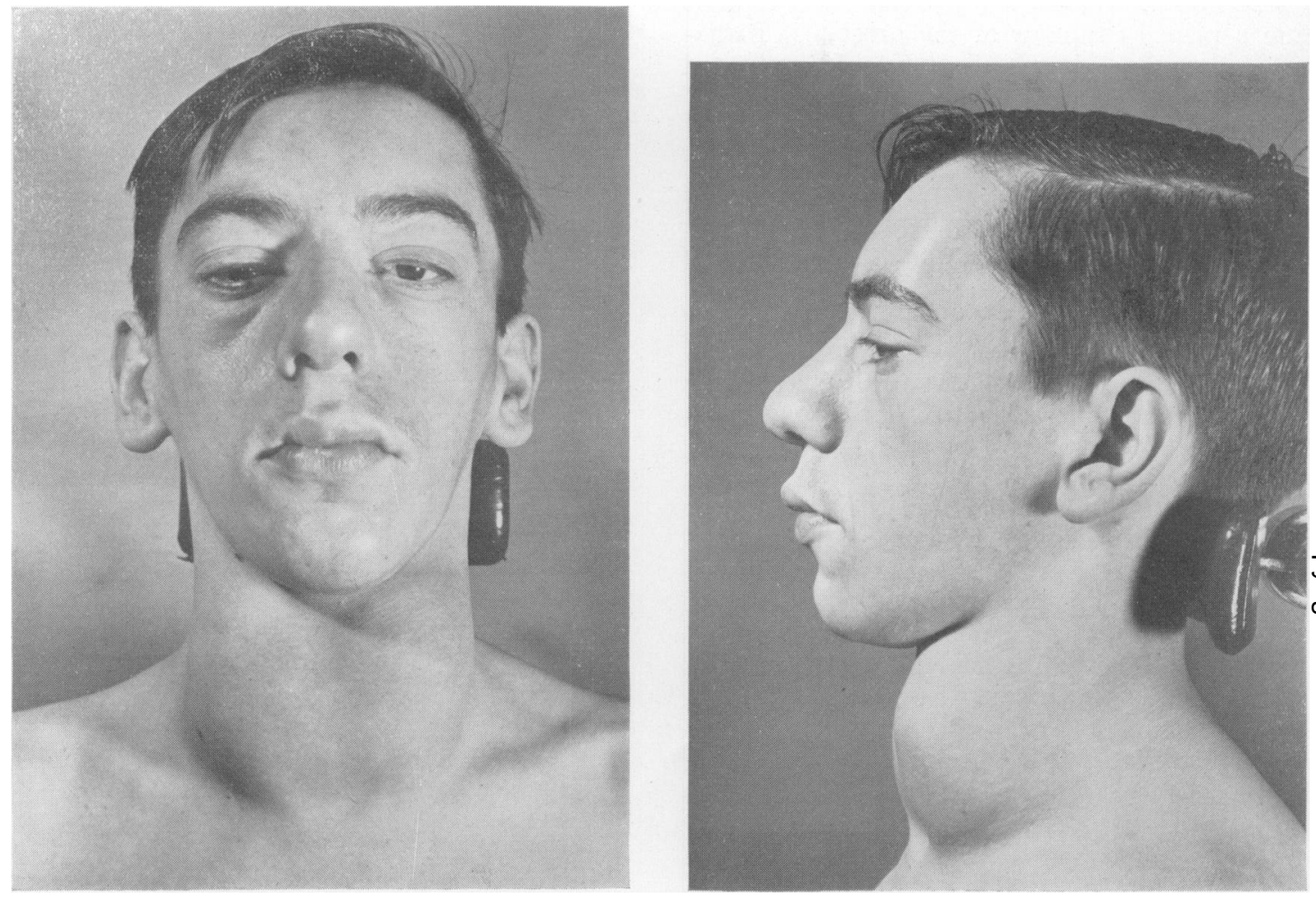

FIGS. 1 and 2.--Patient aged 18 years with a papillary type of thyroid carcinoma.

Carcinoma of the thyroid is not a common disease. In recent years, however, there have been numerous reports that its incidence is higher than has previously been believed, whilst, at the same time, a number of advances have been made in treatment by surgery, goitrogens, $\mathrm{X}$-rays and radioactive iodine. A review of the subject at this time is therefore not inappropriate.

\section{Incidence}

A study of the Registrar-General's returns for England and Wales for the five years 1943-47 reveals that $I, 48 \mathrm{I}$ deaths were attributed to cancer of

* Hammersmith Hospital, Ducane Road, London, W.12. the thyroid. 'This was approximately 300 deaths per annum, the ratio of females to males being 2.8 to I. This is presumably the minimum death rate from this disease. If it is assumed that a diagnosis of malignant disease of the thyroid usually causes the death of the patient harbouring it, $\mathcal{O}$ another way of assessing the frequency of the $N$ disease is to analyse the post-mortem records of a large hospital. Van der Laan (I947) carried out such a review at the Boston City Hospital, Massachusetts, and found that during the half century from 1896 to 1945 , of 18,668 autopsies only five $\stackrel{\infty}{?}$ showed carcinoma of the thyroid gland. A similar review (Van der Laan, I947) of the postmortem material at two other large hospitals in Boston showed an incidence of less than $I$ in $I, 000$. 


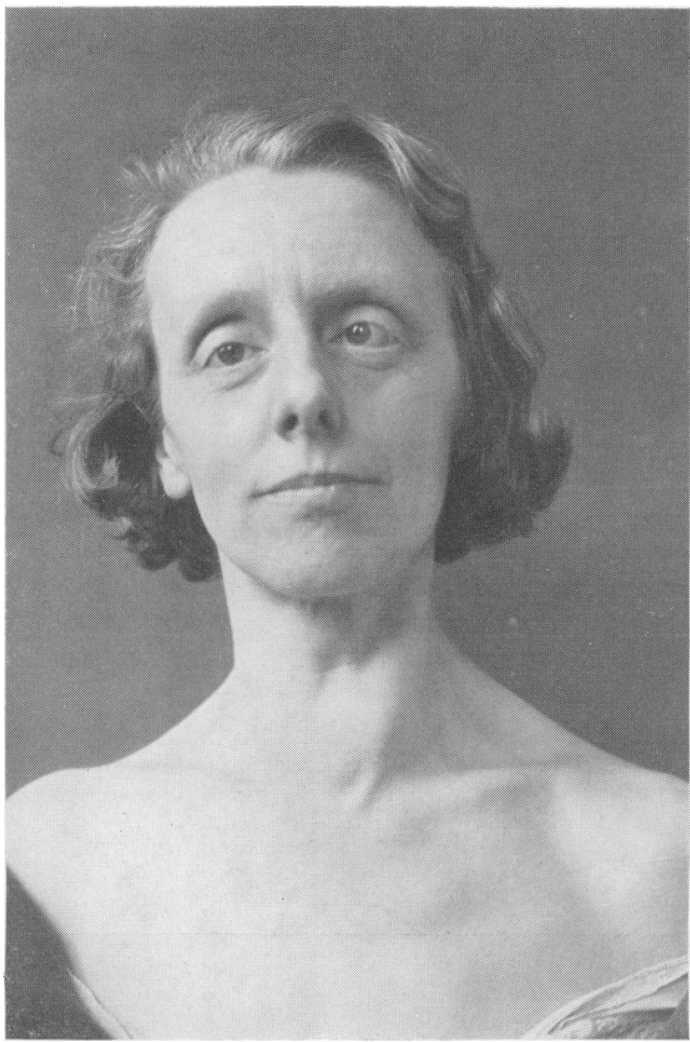

FIG. 3.-Undifierentiated carcinoma of thyroid. Patient aged 42 ; presenting with a swelling in the neck which had been present for only three months.

Such figures are difficult to interpret. Possibly, owing to the duration of the disease, patients of this type commonly die in their own homes.

When a fairly certain diagnosis of malignancy in a goitre can be made clinically, the prognosis is usually hopeless, but many enlarged thyroid glands are removed for a variety of reasons and the diagnosis of carcinoma only arrived at after a microscopical examination. Can a certain diagnosis of malignancy be made on the histological appearances? The answer is no. There are few more difficult problems which confront the pathologist than that of deciding when a nodular goitre has become malignant. Graham (1925) presented what he considered to be the criteria of malignancy in the thyroid; since he insisted on invasion of blood vessels by tumour cells his standards were perhaps too stringent.

\section{Age Incidence}

Three-quarters of all these tumours occur between the ages of 40 and 70 , the average age in

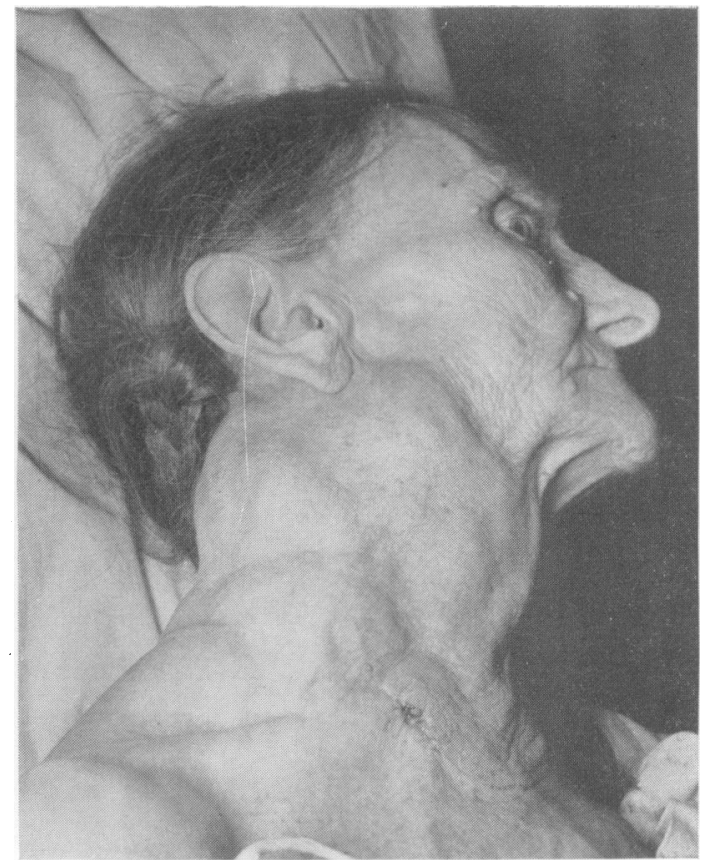

FIG. 4.-A case of solid alveolar adenocarcinoma of the thyroid gland arising in a goitre which had been present for 17 years, the patient being 80 years old when first seen. The incision shows the site of removal of a large pre-tracheal mass which caused urgent dyspnoea.

men being 53 and in women 48 (Pemberton, 1939). However, cancer of the thyroid is occasionally seen in children and young adults when it is usually of the papillary type. Reports from areas where goitre is endemic suggest a younger age incidence, Warren Cole (1945) reports an overall average age of 48 in patients treated in Chicago and presumably drawn from the surrounding state of Illinois.

\section{Sex Incidence}

In general about three females to every male are affected by this disease. The Registrar-General's figures quoted above give a ratio of 2.8 to $\mathrm{I}$; in Joll's (I932) series for I9I 8-30 it was 3 to I. Since enlargement of the thyroid gland is approximately nine times as common in women as in men, the latter show a greater proneness to malignant change.

\section{Incidence of Carcinoma in Goitres}

This depends chiefly on two factors. First, when the patient comes from a region in which goitre is endemic, the incidence is much higher (Crile, 1949) (i) and carcinoma of the thyroid may be described as a geographical disease. Second, 


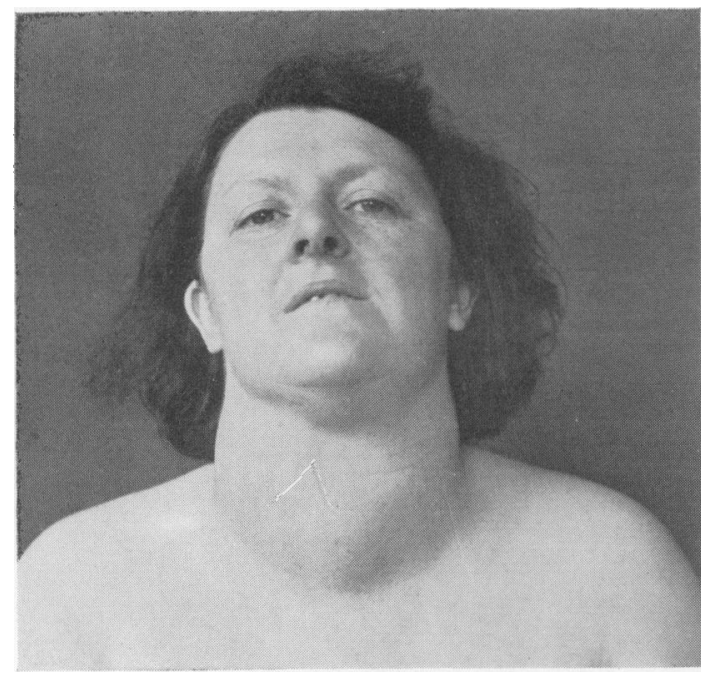

Fig. 5.-Patient aged 37 with an undifferentiated carcinoma of the thyroid. Goitre present for 18 years, rapidly increasing in size in the last 18 months.

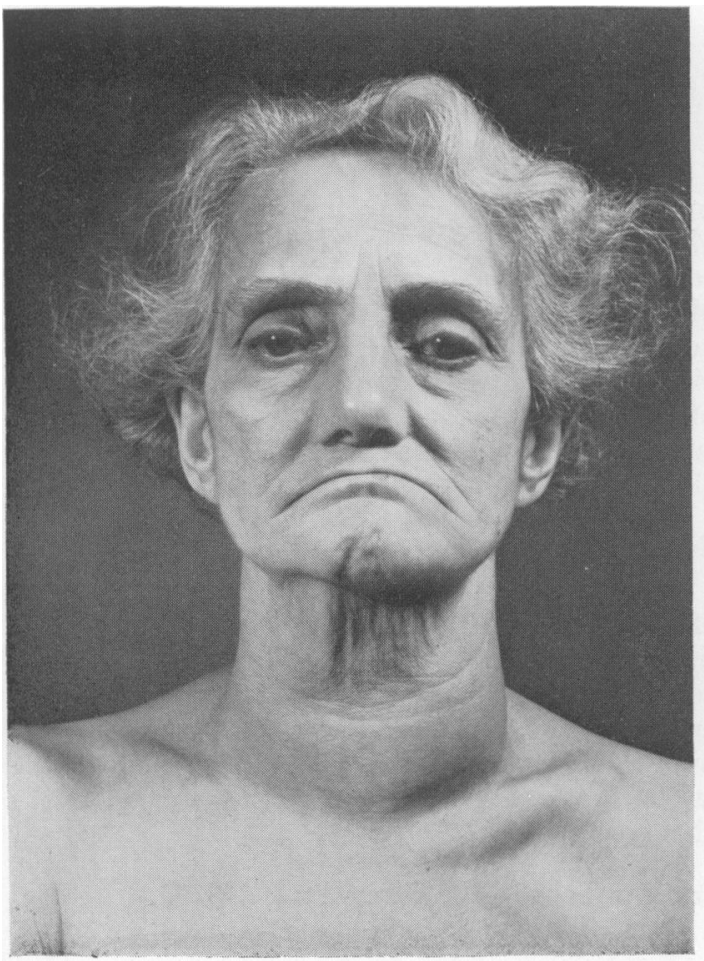

FIG. 7.

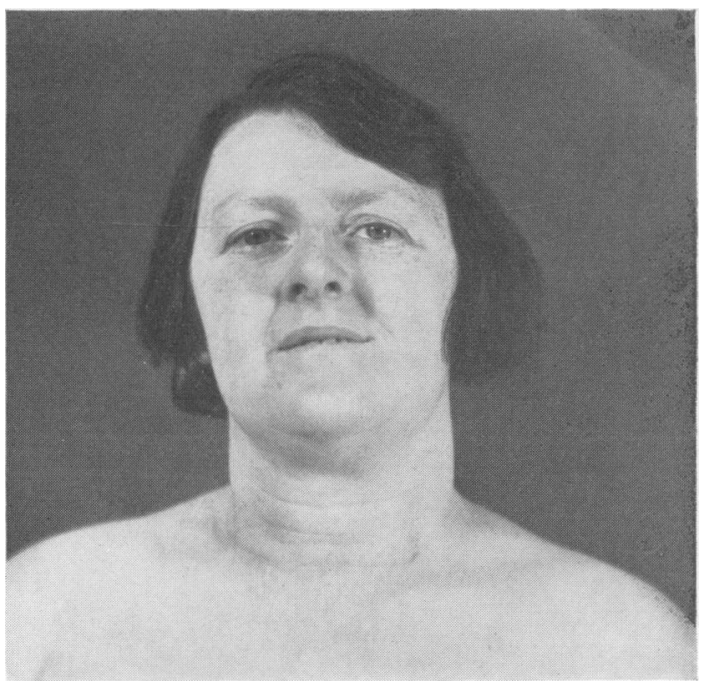

FIG. 6.- Same patient post-operatively and before radiotherapy. This lady was fit and well 18 months later with no evidence of recurrence and having had a normal pregnancy.

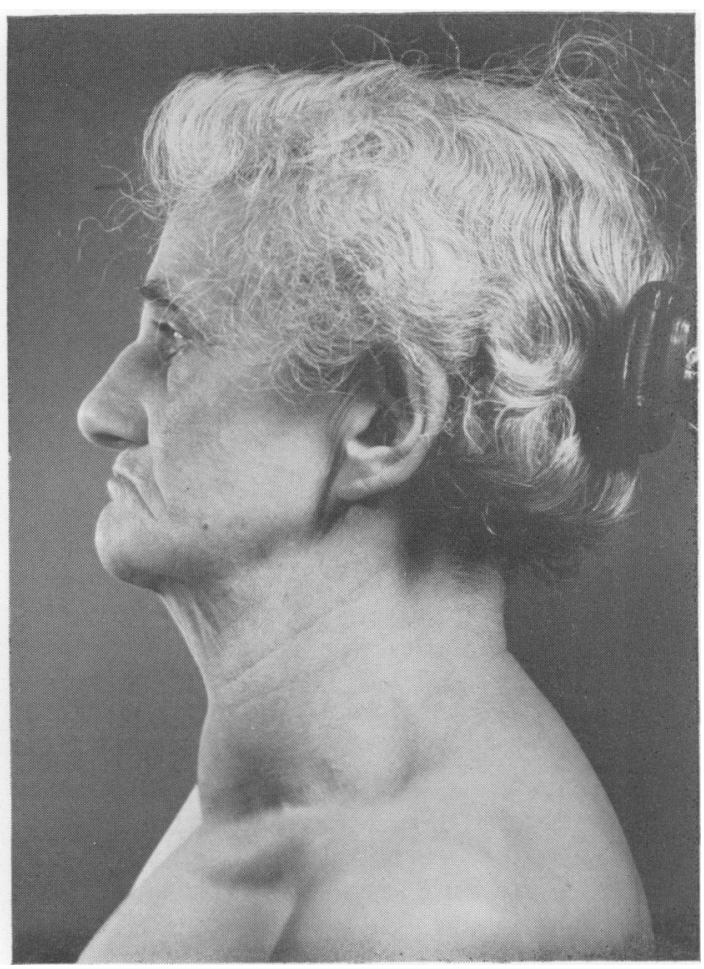

Fig. 8.

FIGs. 7 and 8.-Patient with a goitre of recent origin, fixed to surrounding structures and causing both dyspnoea and dysphagia. At operation a lymphadenoid goitre (Hashimoto's disease) was discovered. 


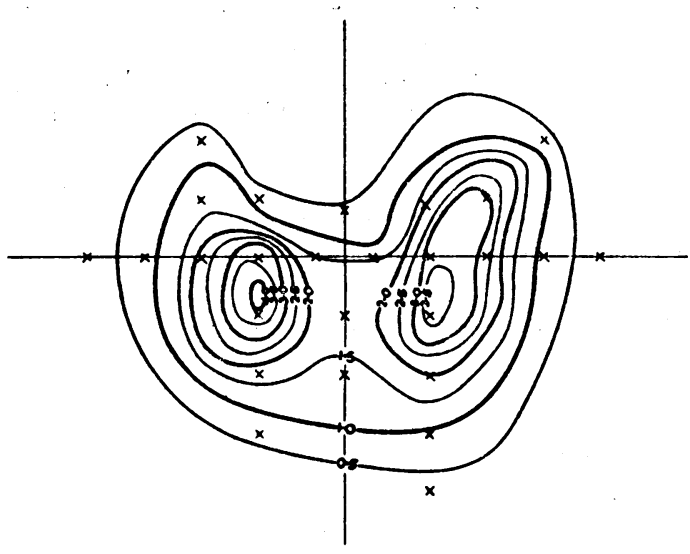

Diagram 1.-Uptake distribution of radioactive iodine by an apparently normal thyroid gland. The contours (isocuries) indicate the per cent. of dose per square centimetre.

the experience of the pathologist in this particular field of histology and his criteria of malignancy are all important (Ward, I949). It is not uncommon for a multinodular goitre to be classified as benign in one laboratory and malignant in another, moreover since some of the slower growing tumours have been known to lie dormant as long as 20 years (Crile, r949) (i), the clinician may be lulled into a sense of false security and believe the gland to be innocent. If these facts are borne in mind the very conflicting statistics appearing from different clinics do not appear so remarkable. Below are given some of the figures which have been published by clinics in the last few years; these show

\begin{tabular}{c|c|c}
\hline Author & $\begin{array}{c}\text { Per Cent. } \\
\text { Single Nodules } \\
\text { Excised, } \\
\text { Found to be } \\
\text { Malignant }\end{array}$ & $\begin{array}{c}\text { Per Cent. } \\
\text { Multiple } \\
\text { Nodular } \\
\text { Goitres Ex- } \\
\text { cised, Found } \\
\text { to be Malignant }\end{array}$ \\
\hline $\begin{array}{c}\text { Warren Cole, et al. } \\
\text { (1945) }\end{array}$ & 24.0 & 17.1 \\
\hline $\begin{array}{c}\text { Warren Cole, et al. } \\
\text { (1949) }\end{array}$ & 24.4 & 17.1 \\
\hline $\begin{array}{c}\text { Crile, G., Jun. } \\
\text { (1949) }\end{array}$ & 24.5 & 10.9 \\
\hline $\begin{array}{c}\text { Cope, O., et al. } \\
\text { (1949) }\end{array}$ & 19.0 & 10.0 \\
\hline
\end{tabular}

that when a solitary nodule in a non-toxic goitre is excised there is approximately a 20 per cent. chance of its being malignant. In the case of a

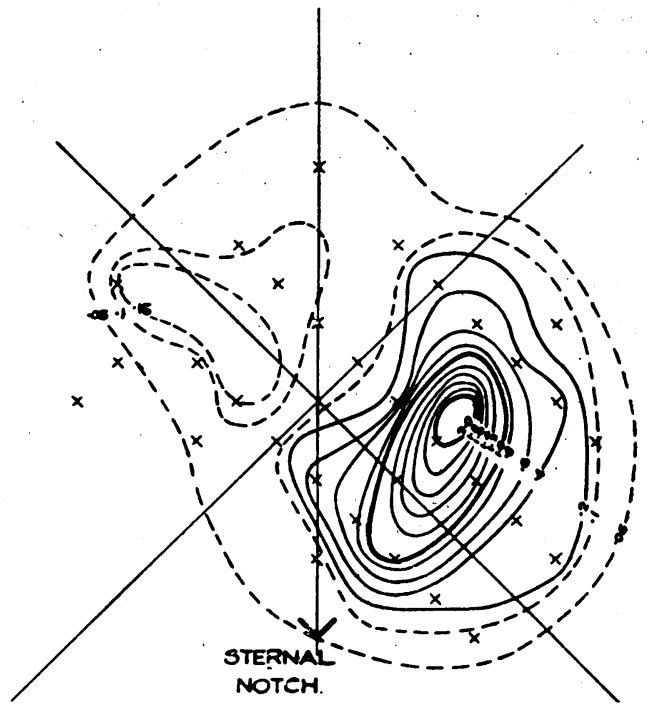

Diagram 2.-Uptake distribution of radioactive iodine by a thyroid gland which had been replaced by carcinoma with the exception of the left lower pole.

multinodular non-toxic goitre the cancer rate is about ro per cent.

These figures by no means represent the true incidence of malignancy in nodular goitres. The patients who eventually have their thyroids excised are a highly selected group of people as Crile (1949) (ii) has so rightly stressed. In the first place they or their family have usually noticed some change in the configuration of the neck, and this has been serious enough to make them consult their own doctor. He, in turn, has referred them to a surgeon or hospital clinic, and only when all these different opinions have recommended operation is the gland excised, since no one wishes to undergo a surgical operation if any alternative exists.

Thus it is quite misleading to say that 10 per cent. of non-toxic multinodular goitres are malignant. What is true is that ro per cent. of the multinodular goitres excised are malignant.

Even if we stress the peculiar selection which must go on to produce these figures they are still disquieting, and there need be no doubt that those reported malignant in Cole's series were correctly diagnosed, since of the 16 in the $1944-48$ series I I were already dead and two of the five remaining had metastases by 1948 .

At this point it is perhaps permissible to digress in order to discuss the pros and cons of removing nodular goitres because of their potential malignancy, In this country Branson and Houston 
(1949) reviewed 530 cases of nodular goitre which had been operated upon by the late Cecil Joll. Among these there were 65 cases of carcinoma, of which 33 were classified as malignant adenomas, i.e. 6 to 12 per cent. were malignant according to the histological diagnosis. The operative mortality was low, and these authors claim that all non-toxic nodular goitres should therefore be removed surgically. Since the patients from whom malignant adenomas had been removed all survived for more than five years, the diagnosis in some of these may well be suspect.

A quite contrary point of view is taken by Crile, from consideration of not dissimilar statistics. He states that about 4 per cent. of all patients arriving at the Cleveland Clinic for non-thyroid reasons are found to have nodules in their thyroids, and he deduces that 6,675 adenomas would have to be removed to prevent one patient dying from thyroid cancer.

The writer does not subscribe to the view that all patients with non-toxic, nodular goitres should be submitted to a surgical operation, although many will require thyroidectomies because the gland causes pressure symptoms or for cosmetic reasons. Nor does he believe that all solitary nodules should be excised, except in the very young. It is important, however, that all such patients should be examined clinically by one well experienced in goitre work and a careful case history taken; if a suspicion of malignancy is still entertained under these circumstances, then a thyroidectomy should be done. The most important observations leading to such a step will be the presence of a single nodule in the thyroid of a young patient, evidence of recent increase in size in a long-standing goitre, the hardness of the nodule or nodules, the occurrence of dysphagia and, not least, the patient's own impression that all is not well in the neck. Recurrent laryngeal nerve involvement is pathognomonic of malignancy, but likewise a late sign.

\section{Pathology}

The very fact that so many different classifications of cancer of the thyroid have been suggested in the past is good evidence that none is wholly satisfactory. It will be found useful to divide these tumours in the first place into two main groups, papillary and non-papillary (Proc. Nat. Cancer Conf., 1949).

Papillary cancer of the thyroid may occur at any age, but shows a decided tendency to occur in the young, possibly the youngest reported being in a child of four years. Typically it is a slow growing tumour and I know of a patient who had a cervical lymph node containing such a metastasis removed I6 years ago, who has had no further symptoms.
Crile reports a patient who harboured a simila? tumour with little increase in size over 27 years.

Papillary carcinoma of the thyroid has a pree dilection for spreading by the lymphatics, especially in younger patients. This accounts for the previous concept that thyroid tissue could appea laterally in the neck as a developmental abnormality the so-called lateral aberrant thyroid. Such tissue is the result of spread of a highly differentiate $\Phi$ papillary tumour into a cervical lymph nodeo (Lahey, 1946; Crile, 1947). The primary growth may be so small that it is only discovered afte? cutting serial sections of the thyroid lobe on th affected side; the title of ' occult carcinoma of the thyroid' has been suggested for such tumours (Wozencraft, 1948).

The non-papillary tumours can be subdivided into groups according to their histological apsi pearance (Wegelin, 1926) or according to theip clinical behaviour (Lahey, 1940).

Histologically they appear as:

(a) Adenocarcinomas with colloid formation? tumours which reproduce fairly faithfully then structure of the parent gland.

(b) Adenocarcinomas without colloid formation less differentiated than the foregoing.

(c) Carcinoma simplex; solid tumours whose cells show varying degrees of differentiation. ?if their most anaplastic form the histological picter of these tumours may be indistinguishable froms sarcoma, though whether sarcoma of the thyrois ever occurs is of academic interest only.

One further tumour requires mention because of its distinctive appearance. This is the so-called Hürthle cell type, which is comprised of eosino $\overrightarrow{\vec{B}}$ philic cells surrounding small alveoli. Williş (1948) has pointed out that it is trebly unfortunate that such tumours should be classified separately and dignified with the eponym Hürthle. Hürth was not the first to describe these cells, since Baker did so 17 years earlier. Hürthle thought that these large pink-staining cells were interfollicular but interfollicular cells probably do not exist as Rienhoff's (1929) wax reconstructions show. Fin ally these cells are probably only a variant of alveola cells and can be found in many other conditions though not in such large numbers (Lennox, 1948).

Clinically the non-papillary thyroid cancers cat be conveniently divided into those which are weht differentiated and show some degree of thyroid function and those which are non-functioning.

The last 28 consecutive cases of thyroid canceF treated at Hammersmith Hospital have include $\$$ five proved cases of papillary adenocarcinoma. Th\& remainder have shown every type of histological picture from the alveolar type with colloid formation to the most undifferentiated variety which, of occasion, was labelled sarcoma. 


\section{Surgery}

The most important form of treatment for almost every case of carcinoma of the thyroid is a surgical operation, but the form which the operation takes must be decided by the variety and extent of the tumour. Once again it is convenient to consider separately two main groups; the papillary and the non-papillary carcinomas.

Papillary carcinoma of the thyroid is essentially slow growing and occurs in the younger age groups. The diagnosis may be made on the operating table when an enlarged lymph node removed from the neck is found to contain metastatic thyroid tissue. When the disease is confined to one side of the neck the lobe of the thyroid gland on that side should be removed in its entirety, no matter how normal it appears, since a primary growth may be only a millimetre in diameter. If the isthmus is involved then the resection will have to include a generous portion of the contralateral thyroid lobe. A decision has then to be made on how radical should be the removal of the lymphatic drainage on the affected side. Here it has to be remembered that the tnmour is usually a slow growing one, the patient often young and very often a girl. Bearing these facts in mind it is not justifiable to carry out a block dissection of the neck, involving as it does removal of the sternomastoid muscle and probably the internal jugular vein, although many surgeons have proposed it (Metzger, 1948). Crile's suggestion that the excision should be local, nonmutilating, and multiple if necessary, is a good one, but not in all patients. If there is involvement of many lymph nodes it is far better to proceed at once to a formal block dissection than run the risk of further operations in the near future in an area distorted by scar tissue. A history of extremely slow progress might modify this view.

Non-papillary carcinomas may present in a variety of different ways. At one extreme the diagnosis of malignancy is not even suspected and a non-toxic, or very rarely a toxic, nodular goitre is excised, the pathologist subsequently reporting an early cancerous change. At the other extreme the unfortunate patient who has had a goitre for many years consults her doctor because her neck has started to enlarge and pressure symptoms have arisen. Such a condition may require tracheotomy, and vet despite this the patient may die in a few weeks.

The treatment of these malignant goitres should follow certain clearly defined basic principles. As soon as the diagnosis of malignancy has been confirmed at operation an attempt is made to do a total thyroidectomy. If successful this serves two purposes; the removal of the primary growth and the removal of all normal functioning thyroid tissue. The latter is of value in that in some patients the anterior pituitary may then stimulate $\frac{\varrho}{3}$ metastases to take on the production of thyroxin $\frac{\mathbb{Q}}{\mathrm{Q}}$ and thus make them accessible to treatment byc. radioactive iodine. Total thyroidectomy in $a$ patient whose thyroid is enlarged and distorted by carcinoma can be a formidable undertaking, more-을 over it is essential to preserve the recurrent laryngeal nerves or at least one of them, and also $\frac{D}{\square}$ the parathyroid glands. If the tumour has spread ${ }^{\mathbb{Q}}$ widely the operator should be content to be radicalo on one side of the neck only, in order that only onevocal cord is jeopardized. Pretracheal muscles. and one internal jugular vein may be sacrificed $\vec{\omega}$ together with all the involved tissue that it is possible to remove; often the tumour can be slicedo off the trachea. If necessary the operation is com $-\frac{3}{3}$. pleted by performing a tracheotomy. Attempts $v$ have been made recently to resect part of the $\omega^{\circ}$ trachea and replace its wall by tantalum gauze + and fascia (Robb, 1949). Two weeks later a block dissection of the lymphatic drainage is made on the side of the neck primarily involved. It may benecessary to repeat this on the opposite side if the tumour was extensive and involving the isthmuso or contralateral lobe.

There are a few patients who have slowly growing cancers and who when first seen preseot $\overrightarrow{0}$ serious signs of obstruction to trachea and great vessels. Often these people are only capable oิ̀f breathing whilst sitting bolt upright and they show great enlargement of their neck veins; surgery for these can only be a palliative, but it is well worth while. They are taken to the operating theatre $\frac{0}{\circ}$ and, if possible, anaesthesia is induced with the patient sitting up, and a tracheal tube passed. As $\overrightarrow{\vec{O}}$ much of the tumour as possible is then cut away, and if necessary a tracheotomy tube is inserted. The latter is by no means always required. The subsequent treatment of these patients is mainly을 by radiotherapy.

Finally there is an anaplastic type of thyroid 3 carcinoma often occurring in middle aged males, which can only be described as fulminating. For these radiotherapy is ideal. Surgical treatment is 0 only indicated in so far as a tracheotomy may be required to spare the patient the agony of death by $\frac{D}{2}$ strangulation. Even after intensive radiotherapy these tumours may fungate through the tracheo- $\mathcal{N}$ tomy opening within the space of a few days. N Fortunately, however, this type of tumour is N usually radiosensitive.

\section{X-ray Therapy}

For many years X-ray therapy has been used ex- $\stackrel{D}{D}$ tensively for the treatment of carcinoma of the thyroid, and an outstanding contribution to this subject was made by Graham and McWhirter $\mathbb{D}$ (1947) in their address to the Royal Society of $\frac{}{D}$ 
Medicine in 1947. They came to the following conclusions after reviewing the treatment given to r44 consecutive unselected cases in Edinburgh.

I. Localized nodules in the thyroid should be removed radically by surgery. If the tumour proves to be an adenocarcinoma or a papillary adenocarcinoma then the value of subsequent therapy is doubtful. If the tumour is an undifferentiated carcinoma then post-operative X-ray treatment should be given.

2. If the whole thyroid is enlarging rapidly the diagnosis is probably an undifferentiated carcinoma and $\mathrm{X}$-ray treatment is indicated using wide fields and including the thorax.

3. A biopsy should be obtained whenever possible to guide treatment, except when rapid growth is causing dyspnoea. Under the circumstances $\mathrm{X}$-ray therapy is started forthwith.

4. In advanced tumours of high malignancy, X-ray treatment should not be accompanied by surgical removal of the accessible part of the cancer.

The three years which have elapsed since these statements were made have seen few advances likely to alter them except in minor details. Phillips (Proc. Nat. Cancer Conf., r949) at the Memorial Hospital, New York, treats highly malignant tumours with $4,000 \mathrm{r}$ in four weeks, and though cures do not result the patients usually die of metastases involving liver and lung. When a solitary lung deposit causes troublesome haemoptysis it is treated palliatively with $2,000 \mathrm{r}$ given over ten days. Such a technique is useless when multiple secondaries are present. Pre-operative irradiation of the neck with 2,000r for ten days was given to the so-called malignant adenoma and operation carried out on the IIth day. Postoperative $\mathrm{X}$-rays were not indicated since when secondaries appeared they were rarely locally in the neck. Patients with papillary adenocarcinomas, howeve:, were given post-operative irradiation since their spread was usually to the local lymph nodes; if they recurred after some years, $3,000 r$ was given over a period of three weeks both to the lower two-thirds of the neck and the mediastinum.

\section{Radioactive Iodine}

The opening of a chain-reacting pile at Harwell has resulted in there now being available a plentiful supply of radioactive isotopes for research and therapy in medicine. The thyroid is ideally suited above all other tissues in the body for treatment by radioactive material, since it has the unique property of extracting from the blood stream circulating iodine. In addition this iodine is then concentrated in the gland and stored within the vesicles for gradual liberation as required, in the form of thyroxine.
Stable iodine is usually designated as $\mathrm{I}^{127}$, and already many radioactive isotopes of this element have been discovered. The one which has proved most suitable for work with the thyroid is $I^{\mathbf{1 3 1}}$, which has a half life of eight days; this means that half the molecules in any sample will have given off their radioactivity by the end of eight days.

$I^{131}$ is prepared in the pile by the bombardment of metallic tellurium with slow neutrons according to the following reactions:

$$
\begin{gathered}
{ }_{52} \mathrm{Te}^{130}+{ }_{0} \mathrm{n}^{1} \rightarrow_{52} \mathrm{Te}^{131}+\gamma \\
{ }_{52} \mathrm{Te}^{131} \rightarrow_{53} \mathrm{I}^{131}+\beta
\end{gathered}
$$

The $\mathrm{Te}^{131}$ has a half life of only 25 mins. and thus rapidly becomes $I^{131}$. It is necessary to study how $\mathrm{I}^{131}$ decays in order to know what kinds of radiation it gives out when taken up by the thyroid. In fact, physicists have not yet solved this problem completely, but Metzger and Deutsch (I948) have recently proposed a rather complicated explanation. The net result is the emission of $\gamma$ rays of varying intensity and moderately hard $\beta$ rays. The $\gamma$ rays are extremely penetrating and can be measured by a Geiger-Müller counter placed some distance away from the source, thus enabling one to count radiations over the neck. The $\beta$ rays, which account for the greater part of the radioactivity of $\mathrm{I}^{131}$, only penetrate about $2 \mathrm{~mm}$. in the thyroid and cannot therefore be detected outside the neck even if the thyroid is immediately under the skin.

In the body the radioactive element $I^{131}$ behaves in precisely the same manner as the stable form $\mathrm{I}^{127}$ and is concentrated in the thyroid gland. It is of importance that radioiodine can be prepared in the atomic pile free from stable iodine (i.e., carrierfree) because then, when a dose of radioiodine is given to a patient, it will be known that the iodine taken up by the gland is the radioactive isotope.

The value of radioiodine in cancer of the thyroid is twofold. It may be used as an aid in diagnosis and, on rare occasions, for the treatment of thyroid metastases.

\section{Radioiodine in Diagnosis}

A substantial number of patients with thyroid cancer have now been investigated with radioiodine and the number showing uptake of radioiodine by the tumour cells is small. Fitzgerald (1949) gave 100 patients radioiodine and 46 showed some concentration in the tumour cells, but in none was it equal to the concentration in the uninvolved thyroid. Because of these two observations it will be seen that if a patient is given a tracer dose and a directional Geiger-Müller counter is used to scan the activity in the neck, should a nodule show markedly less activity than the surrounding thyroid tissue it raises the pos- 
sibility that the nodule may be malignant (Dobyns, 1949).. Such a finding is no more than suggestive, but it is of real value since the surgeon who knows of this before operation can be prepared to carry out a radical excision.

At this hospital a method of mapping out the function of the thyroid gland (Taylor, 195I) has been evolved, using a collimated counter designed by Veall (1950) and a tracer dose of only 100 microcuries. The appearance of a normal gland using this technique is shown in Diagram $\mathbf{1}$; and that of a gland containing carcinoma in the right lobe in Diagram 2. It will be seen that the only. functioning tissue in the latter is that at the left lower pole, which was found at operation to be the only part of the gland not replaced by tumour. The finding by such a method that part of a
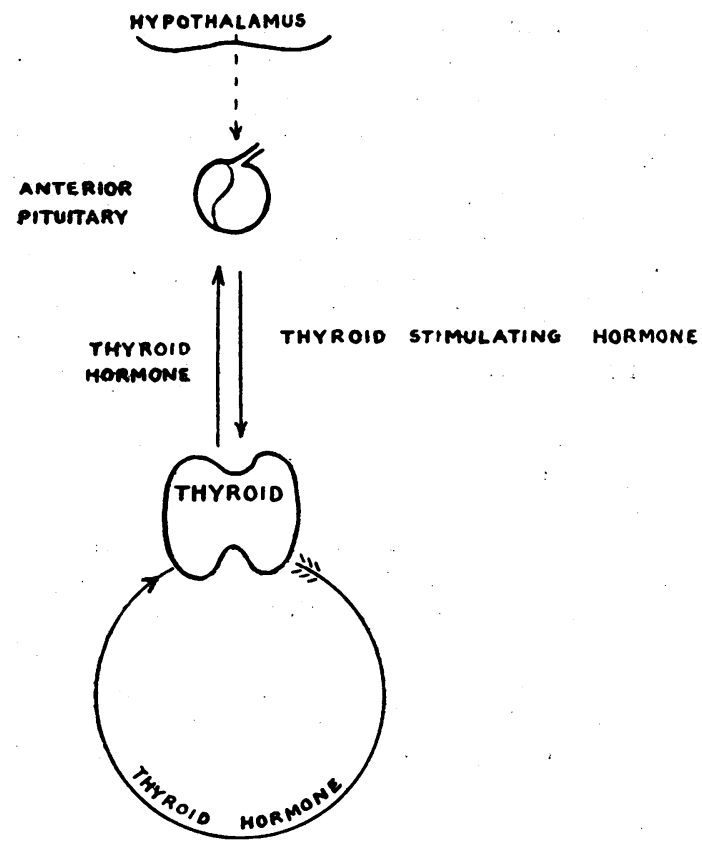

DIAGRAM 3 (above).-Pituitary-thyroid axis showing diagrammatically the interaction of these endocrine glands.

DIAGRAM 4 (right).-Pituitary-thyroid axis shown

- diagrammatically in a patient after excision of the thyroid for carcinoma with the presence of metastases which are taking on thyroid function. thyroid does not take up radioiodine is no more than suggestive of malignancy, since it might occur in many other pathological states. ' It may be of value, however, when considered in conjunction with all the other signs, symptoms and investigations.

\section{Radioiodine Therapy}

Radioiodine can only be used for the treatment of thyroid cancer if the tumour cells take up enough of the isotope to irradiate themselves adequately. Since almost all such tumours take up less iodine than the parent gland it is necessary to find some means of stimulating their activity. If we assume that the diagram (Diag. 3) represents in simplified form the balance maintained in the body between the pituitary and

\section{ANTERIOR PITUITARY}
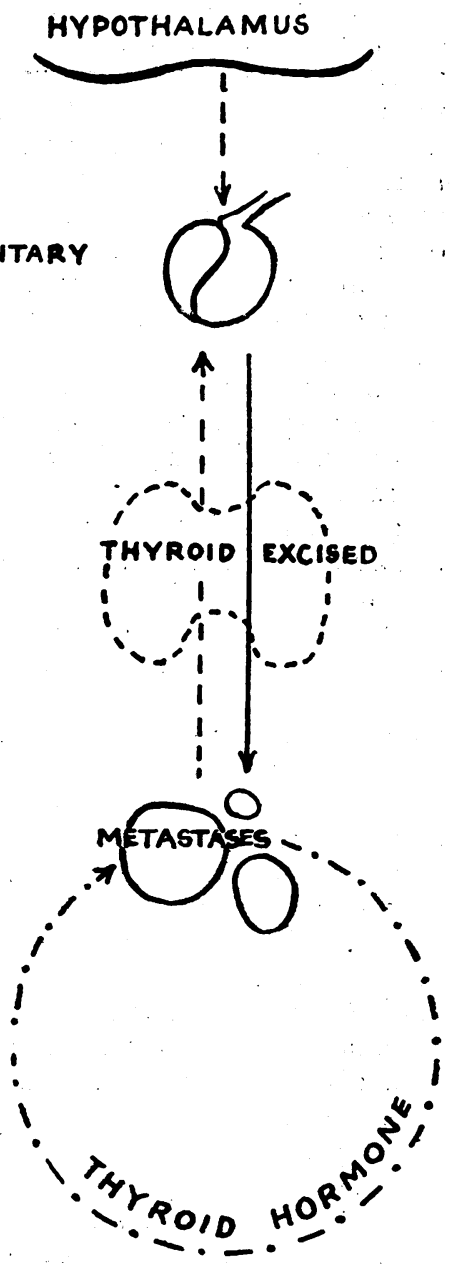
thyroid gland, then the best stimulus to the tumour cells to take on thyroid activity will be complete removal of the gland, since by this means there will be lack of thyroxine in the blood stream. This will lead to overactivity of the anterior pituitary and the production of thyroid stimulating hormone (TSH), the latter inducing the tumour cells to manufacture thyroxine if they are in fact capable of so doing. The importance of this mechanism was first pointed out by Rawson et al. (1948) and is illustrated in Diag. 4 .

The practice of giving patients with carcinoma of the thyroid a tracer dose of radioiodine in order to see if the tumour or its metastases take up significant amounts is therefore not of much value. It gives no indication of how the metastases will behave after any normal thyroid tissue has been removed. In order to use radioiodine to irradiate malignant thyroid tissue it is necessary first to destroy any normal thyroid cells. Clearly the best way of removing thyroid tissue is by a surgical operation since this serves three purposes: It reveals the extent of the primary growth, provides the pathologist with adequate material for histological examination and permits an attempt to be made to eradicate the tumour. In frail patients who are unlikely to stand the strain of such an operation it is justifiable to give a dose of radioiodine calculated to destroy all the normal functioning thyroid tissue. This will usually be of the order of 40 to 80 millicuries, and overdosage is permissible under the circumstances.

The proportion of patients who benefit under this plan of treatment is small. During the last 12 months at the Christie Hospital, Manchester (Warrington, 1950), 2 I patients were seen with cancer of the thyroid and 8 took up a significant amount of radioiodine. It is possible that patients' lives are prolonged under such circumstances and it is a great advantage that the treatment consists merely of drinking a glass of water containing $l^{131}$ with practically $r o$ toxic effects.

The treatment of these patients can be carried yet a stage further by various methods for stimulating the metastases to take on increased thyroid function after total thyroidectomy. Two different lines of attack have so far produced satisfactory results. The first, and perhaps most obvious, is the injection of thyroid stimulating hormone (TSH) for a number of days before giving the radioiodine, following which a significantly greater uptake has been reported (Seidlin, 1948). The second method consists of giving really large doses (up to 2 gm. per day). of methyl thiouracil for a month or longer, this appears to produce changes in the metastases comparable with those that occur in the normal thyroid gland, i.e. disappearance of colloid, increase of acinar cell height, increased vascularity and overall size of tumour. The thiouracil is then stopped for two days, the block to thyroxine formation is thus released and on administering the radioiodine a substantially increased uptake is recorded (Trunnel, et al., 1949).

Ever since Von Eiselsberg (1894) first described a patient with hyperfunctioning thyroid metastases, such cases have always held a fascination for the thyroidologist. The introduction of radioactive iodine has made them almost ideal patients for isotope therapy and the first example of a happy result from such treatment is the patient reported by Seidlin (1946). Unfortunately this type of thyroid carcinoma is excessively rare.

The value of radioiodine in the treatment of thyroid cancer can be summarized as follows:

I. The principal use of radioiodine is in the treatment of metastases.

2. Only those metastases which will take up, or can be made to take up, radioiodine can be treated.

3. Less than 50 per cent. of all thyroid tumours take up radioiodine.

4. No tumour concentrates radioiodine as effectively as normal thyroid tissue.

5. The most important preliminary to this form of treatment is the removal by surgery or the destruction by radioiodine of all normal functioning thyroid cells, in order that the metastases can be stimulated to take on thyroid function.

6. The radioiodine uptake of the metastases can be further stimulated by the prolonged administration of methyl thiouracil in large dosage, which is then stopped at least 48 hours before giving the radioiodine.

7. A rare form of thyroid cancer produces metastases with hyperfunction and these are ideally suited to isotope treatment.

8. No patient with thyroid cancer treated by this technique is known to have been cured, but many have been relieved of all their symptoms for varying periods.

9. Autoradiographs prepared from tumour tissue removed from treated patients show a very uneven distribution of the isotope, demonstrating that the irradiation which takes place is not at all uniform.

Io. The use of radioiodine in treatment of this kind requires the services of a physicist and fairly elaborate apparatus for its measurement. It is not without dangers for the patient, the most important of these being suppression of bone marrow activity. It is likewise not without dangers for those who handle it and requires a form of discipline in the clinician using it which he may find difficulty in adopting.

\section{Experimental Thyroid Tumours}

The administration of thiourea or thiouracil to 
rats and mice over a long period leads to tumour formation (Money, 1946). The first changes in the thyroid are those of increased cell height, disappearance of colloid and greater vascularity. Then the epithelium throws out papillary processes into the acini and hypertrophy of these papillae eventually progresses to adenoma formation. Occasionally one of these experimentally produced nodular goitres develops a true carcinoma (Purves and Griesbach, 1947), but it must be remembered that the thiouracil has to be administered to the animal for a time which, when translated into terms of man, would represent a considerable part of his life's span.

Such spontaneous cancers in thiouracil goitres in animals are rare. If, however, a carcinogen is given to the animals in addition to the thiouracil, thyroid cancer may be produced more readily. Bielschowsky (1945) produced such tumours by giving rats allyl-thiourea and 2-acetyl-aminofluorene. It has also been shown that radioiodine when administered to mice treated over a long period with thiouracil can produce malignant tumours (Doniach, 1950). This is a most disturbing observation since both these, thiouracil and radioiodine, are in everyday use for the treatment of thyrotoxicosis. Fortunately it appears that these substances have to be used in considerably larger doses and for longer periods than is normally the case in man, but clearly it will be necessary to have much more information on this subject. It is particularly important to know what will be the long term results of giving radioiodine in therapeutic doses to patients with toxic goitres. Until statistics are available covering a period of 20 years it may well be inadvisable to give radioiodine for the treatment of Graves' disease in young people unless there were very good reasons for it, e.g. severe heart disease or previous multiple operations on the neck.

\section{Summary}

\section{Prophylaxis}

The prevention of nodular goitre will inevitably decrease the incidence of cancer of the thyroid, since often this develops in a longstanding goitre. The introduction in Britain this year of a small quantity of iodine into domestic salt as recommended by the Medical Research Council will be a help in this direction.

\section{Diagnosis}

A careful case history and a thorough examination, especially of the neck, offer the best chance of providing the diagnosis. Solitary nodules in nontoxic goitres, especially in younger patients, should always raise the strongest suspicion of malignancy.
Radioiodine may be of some assistance, since malignant tissue will pick up little if any in contrast to normal thyroid tissue. Thus if, after a. tracer dose, the neck is carefully scanned with a directional Geiger-Müller counter and a thyroid nodule is found to have no activity, the possibility of malignancy might be entertained.

The histological examination of tissue removed from the thyroid gland will always be necessary for a firm diagnosis. Even then the pathological picture may still give rise to varying interpretations and it may be many years before the behaviour of the tumour makes the correct diagnosis possible.

\section{Treatment}

The first and foremost form of treatment in carcinoma of the thyroid, whether it be overt or only suspected is, with rare exceptions, surgical excision. There are three good reasons for this. First, it may prove possible to excise the tumour completely and thus offer the patient the best chance of a cure. Secondly, tissue is removed which can be examined by a pathologist so that an accurate diagnosis is obtained. Thirdly, should the tumour be- a well-differentiated type of adenocarcinoma with metastases, the removal of the parent gland may result in the metastases taking on thyroid function and thus make them capable of treatment with radioiodine.

The operation performed will depend on the type of tumour encountered. A solitary nodule is best removed with that lobe of the gland in which it is found. A papillary carcinoma in a younger patient is best dealt with by hemi-thyroidectomy and multiple non-mutilating incisions for excising the affected lymph nodes as and when they become involved. If the lymph nodes are widely involved a block dissection of that side of the neck completes the operation. Adenocarcinoma is treated, where possible, by total thyroidectomy and subsequent block dissections of the cervical lymph nodes when they are found clinically to be involved.

Finally there is a small group of patients who present with rapidly growing tumours. Surgery for such patients does not prolong life and makes them no more comfortable. Even when a tracheotomy is performed, tumour cells may start fungating out of the opening within a short time. Such patients are best treated with $\mathrm{X}$-ray therapy from the start, since the tumour occasionally regresses temporarily and the development of mediastinal metastases makes their demise less unpleasant than if they are choked to death.

Radiotherapy can also be used with advantage in those patients who have surgical ablation of the tumour. Metastases to lymph nodes in the neck may be particularly suitable for irradiation. In 
addition radiotherapy offers useful palliation, especially where a solitary metastasis in a lung is producing haemoptyses.

Radioiodine is used in those patients whose metastases take on function after total thyroidectomy. It may prolong life and greatly increase the patient's sense of well being. Probably not more than 15 per cent. of all patients with carcinoma of the thyroid gland seen at the present time are capable of being treaied in this manner.

\section{BIBLIOGRAPHY}

A very large number of articles has appeared on the subject of thyroid carcinoma in the last few years, and the references given below are not intended in any way to be a comprehensive list. The aim has been to give some of the more important contributions to thyroid literature which will serve as a guide to anyone wishing to discover more about this subject. The most useful general accounts will be found in 'The Thyroid Gland' by J. H. Means; 1948; 'Practical Aspects of Thyroid Disease' by G. Crile, r949; and the section on the thyroid in the 'Proceedings of the National Cancer Conference' held at Memphis in 1949.

BIELSCHOWSKY, F. (1945), Brit. F. exper. Path., 26, 270. BRANSON, K. M., and HOUSTON, W. (1949), Lancet, ii, 979. CATTELL, R. B. (1950), Ұ. Clin. Endocrinol., 10, 1099.

COLE, W. H., SLAUGHTER, D. P., and ROSSITER, L. J. (1945), F. Amer. med. Ass., 127, 883 .

COLE, W. H., MAJARAKIS, J. D., and SLAUGHTER, D. P. (1949), $\mathcal{F}$. Clin. Endocrinol., 9 , 1007

COPE, O., DOBYNS, B. M., HAMLIN, E., and HOPKIRK, J. (1949), Ibid., 9, 1012.
CRILE, G., JNR. (1947), Surg. Gynec. Obstet, 85, 757.

CRILE, G., JNR. (I949), 'Practical Aspects of Thyroid Disease, Philadelphia, p. 226.

CRILE, G., JNR. (1949), Ibid., pp. 236-237.

CRILE, G., JNR. (1949), Ibid., Chapter 24.

CRILE, G., JNR. (1949), 手. Amer. med. Ass., 139, 1247.

CRILE, G., INR. (1050) 7 . Clin. Endocrinol. 10, 1152.

DOBY G., clin Endocr., (1949), $\mathcal{F}$ DONIACH, I. (1950), Brit. F. Cancer, 4, 223.

DONIACH, I. (1950), Brit. F. Cancer, 4, 223. W.' (1949), F. Clin Endocrinol., 9, II 53 .

GRAHAM, A.'(1925), Ann. Surg., 82, 30.

GRAHAM, A. (1941), Radiology, 37, 521.

GRAHAM, J. M., and MCWHIRTER, R. (1947), Proc. Roy. Soc Med., 40, 669.

JOLL, C. (1932), ' Diseases of the Thyroid Gland,' London.

LAHEY, F. H., HARE, H. F., and WARREN, S. (1940), Ann Surg., i12, 977.

LAHEY, F. H., and FICARRA, B. J. (1946), Surg. Gynec. Obstet, $\overrightarrow{0}$

82,705. B. (1948), 7. Path. Bact., 60, 295.

METZGER, F., and DEUTSCH, M. (1948), Physiol. Rev., 74. 1640.

MONEY, W. L. (1946), Anat. Rec., 96, 48.

PEMBERTON, J. DE J. (I939), Surg. Gynec. Obstet., 69, 417.

'Proceedings of the National Cancer Conference, Cancer of the Thyroid' (1949), Memphis.

PURVES, H. D., and GRIESBACH, W. E. (1947), Brit. f. experin

RAWath., 28, ${ }^{46}$ 'W., MARINELLI, L. D., SKANSE, B. M. TRUNNEL, J., and FLUHARTY, R. G. (1948), 手. clin: Endocr., 8, 826.

RIENHOFF, W. F. (1929), Arch. Surg., 19, 986.

ROBB, C. G., and BATEMAN G. H.' (1949), Brit. F. Surg., 37, SEIDLIN, S. M. MARINELLI, L. O., and OSHRY, E. (1946)?

F. Amer. med. Ass., 132, 838 .
SEIDLIN, S. M., OSHRY, E., and YALLOW, A. A. (1948), $\mathfrak{f}_{7 T}$ Clin. Endocrinol., 8, 423 .

TAYLOR, S., and STEWART, F. S. Unpublished data.

TRUNNEL, J. B. MARINELLI, L. D. DUFFY, B. J., HILL R., PEACOCK, W., and RAWSON, R. W. (1949), F. cling Endocr. 9 ,

VAN DER LAAN, W. P. (1947), New Eng. 7. Med., 237, 221 ₹

VEALL, N. (I050), In the press. New Eng. F. Med., 237, 221

VON EISELSBERG (1894), Arch. klin. Chir., 48, 489. 응

WARD, R. (1949),, . Clin. Endocrinol., 9, 1031.

WARRINGTON, H. C. (1950), Lancet, i, 212.

WEGELIN, C. (I926), 'Handbuch der speriellen pathologischer Anatomie und Histologie', Vol. VIII, Berlin.

WILLIS, R. A. (1948), 'Pathology of Tumours,' London, p. 607

WOZENCRAFT, P., FOOTE, F. W., and FRAZELL, $\mathbf{E}$. I I (I948), Cancer, $1,574$.

\section{ANNOTATION}

\section{The Pbosphatases}

\section{Alkaline Phosphatase}

In 1923 Dr. R. Robison, of the Lister Institute, London, began a series of experiments on the phosphatase enzyme of bone, which has led to a clearer conception of the process of bone formation and a better understanding of the mechanism of calcium and phosphate deposition. The enzyme, which is shown to be present in bone and ossifying cartilage, can be extracted by breaking up the bone and treating with chloroform water. This extract, added to a solution of a primary ester of phosphoric acid, will liberate phosphorus from its organic combination: and in the presence of inorganic calcium the liberated phosphate is deposited as calcium phosphate. Robison suggested that the bone enzyme in the hypertrophic cells of the tissue where calcification takes place liberates free phosphate from the organic esters of phosphorus contained in the fluids bathing the bone and? cartilage, thus giving a local increase of the amount of inorganic phosphate in solution. According tọ the law of mass action any increase in the con+v centration of phosphate ion will, in the presences of the ionic calcium of the plasma, lead to deposition of bone salt. This bone enzyme phos phatase is invariably present in bone or ossifying cartilage, while unossifying cartilage fails to show any phosphatase activity. Young, rapidly-growing 